\title{
An anatomical perspective of human occipital condyles and foramen magnum with neurosurgical correlates
}

\author{
Divya Mahajan', Gaurav Agnihotri ${ }^{2}$, Abha Sheth ${ }^{1}$, Rahat Brar ${ }^{3}$ \\ ${ }^{1}$ Department of Anatomy, Dr. H. S. Judge Institute of Dental Sciences \& Hospital, Punjab University, Chandigarh, India \\ ${ }^{2}$ Department of Anatomy, Government Medical College, Amritsar, Punjab, India \\ ${ }^{3}$ Consultant Radiologist, Fortis Hospital, Mobali, Punjab, India
}

\begin{abstract}
Objectives: Knowledge of condylar anatomy helps the surgeon in making important decisions regarding extent and direction of condylar drilling and minimizing injury and retraction of neural structures. Important preoperative information includes length, width, axis/directions and overriding of occipital condyle in foramen magnum, relationships of condyles to foramen magnum and to hypoglossal canal. The anteroposterior and transverse diameters of foramen magnum and amount of overriding of occipital condyle in foramen magnum are useful in calculating area of surgical field. The present study aims to provide important anatomical parameters for the far lateral transcondylar approach.

Methods: The morphometric analysis of human occipital condyles and foramen magnum in 126 dried human skulls and 50 separated occipital bones was performed. The parameters significant to the far lateral transcondylar approach were measured using a digital vernier caliper. In addition, morphometric analysis was also done on 40 patients using thin section CT scans. The paired 't'test was performed.

Results: The difference between the measurements for the right side and left side and those done on CT scans and using vernier calipers on bones came out to be statistically insignificant ( $p>0.05)$.

Conclusion: The far lateral transcondylar approach provides better exposure of the ventrolateral foramen magnum and inferior clivus. Lesion removal from this site can be considerably made easier by utilizing a shorter and widened angle of exposure. Preoperative assessment using CT imaging facilitates the far lateral transcondylar approach without damage to vital functional structures.
\end{abstract}

Key words: foramen magnum; morphometry; occipital condyles

Anatomy 2012-2013;6-7:29-33, (c) 2012-2013 TSACA

\section{Introduction}

Resection of lesions in lower brain stem and ventral surface of craniocervical junction is extremely challenging. A number of surgical access routes to this region are currently in use. Immediate and optimal exposure to foramen magnum, craniocervical junction, clivus and front of lower brain stem is possible using either anterior or lateral / posterolateral approach methodology. ${ }^{[1]}$ Far lateral transcondylar approach is recognized as an optimal approach to access this region. ${ }^{[-5]}$ The transcondylar approach is an extension of basic far lateral approach. ${ }^{[6,7]}$
Basic far lateral approach includes dissection of muscles of the back and the suboccipial triangle, adequate exposure of $\mathrm{C} 1$ transverse process and posterior arch of atlas, identification of vertebral artery above the posterior arch of atlas and a suboccipital craniotomy with removal of at least half of posterior arch of atlas. ${ }^{[8]}$ Transcondylar extension of far lateral approach in addition includes the condylar drilling. It increases the area of surgical exposure and provides access to the lower clivus and premedullary area.

The important anatomical consideration for condylar drilling includes relationships of occipital condyles to 
foramen magnum, hypoglossal canal and vertebral artery. The study was done to provide the important morphometric parameters useful for the far lateral transcondylar approach. The foramen magnum is a vital component of skull base and its morphological considerations are imperative for anatomists, clinicians, forensic and anthropological experts. ${ }^{[9]}$

\section{Material and Methods}

The morphometric analysis was performed on 126 dried skulls and 50 occipital bones (separated) of North Indian subjects (Table 1). In addition, certain morphometric parameters were measured from 40 cases of thin section CT scans (Table 2). CT scans were performed on 23 males and 17 females in the age group of 21 to 43 years. The study was conducted in Dr. H. S. Judge Institute of Dental Sciences \& Hospital, Punjab University, Chandigarh. All the measurements were taken with a digital vernier caliper (least count $0.01 \mathrm{~mm}$ ).

Table 1

Parameters measured on bones

- Length of long axis and width of the occipital condyles (1a \& $1 \mathrm{~b}$ )

- Anteroposterior and transverse diameters of foramen magnum (2a \& 2b)

- Overriding of the medial border of occipital condyle into the foramen magnum (3)

- Distances from the anterior midline of foramen magnum to posterior end and the midpoint of the medial border of occipital condyles (4a \& 4b)

- Distances from the posterior midline of foramen magnum to the posterior end and the midpoint of the medial border of occipital condyles (5a \& 5b)

- Distance of outer and inner foramen of hypoglossal canal to the midpoint of the medial border of occipital condyle ( $6 a$ \& $6 b)$

Table 2

Parameters measured on CT Scans

- Length of long axis and width of the occipital condyles (CT 1a \& 1b)

- Anteroposterior and transverse diameters of foramen magnum ( CT 2a \& 2b)

- Distances from the anterior midline of foramen magnum to the posterior end and the midpoint of the medial border of occipital condyles (CT $4 a$ \& 4b)

- Distances from the posterior midline of foramen magnum to the posterior end and the midpoint of the medial border of occipital condyles (CT 5a \& 5b)

\section{Results}

The measurements on occipital condyles and skulls were done using vernier calipers and the parameters for CT scans were taken from the monitor (Figures 1-5). The results have been depicted in Table 3 and Table 4, respectively. The difference between the measurements for the right side and left side and those done on CT scans and using vernier calipers on bones was statistically insignificant $(\mathrm{p}>0.05)$.

Table 3

Measurement values for bones as taken by vernier calipers

\begin{tabular}{|c|c|c|c|}
\hline Parameter & Side & Mean \pm SD $(\mathrm{mm})$ & Range (mm) \\
\hline \multirow[t]{2}{*}{$1 \mathrm{a}$} & Right & $22.61 \pm 2.3$ & $18.51-28.7$ \\
\hline & Left & $22.36 \pm 2.3$ & $15.24-27.43$ \\
\hline \multirow[t]{2}{*}{$1 b$} & Right & $13.72 \pm 1.56$ & $10.4-17.2$ \\
\hline & Left & $13.96 \pm 1.82$ & $10.8-16.8$ \\
\hline $2 a$ & & $32.83 \pm 2.62$ & $26.06-39.59$ \\
\hline $2 b$ & & $27.47 \pm 2.25$ & $21.65-34.83$ \\
\hline \multirow[t]{2}{*}{3} & Right & $7.01 \pm 1.92$ & $0-10.1$ \\
\hline & Left & $6.95 \pm 1.65$ & $0-9.47$ \\
\hline \multirow[t]{2}{*}{$4 a$} & Right & $26.07 \pm 2.00$ & 20.16-31.16 \\
\hline & Left & $25.75 \pm 2.18$ & 19.79-31.66 \\
\hline \multirow[t]{2}{*}{$4 b$} & Right & $14.87 \pm 1.42$ & 11.32-16.37 \\
\hline & Left & $14.63 \pm 1.39$ & 11.19-15.74 \\
\hline \multirow[t]{2}{*}{$5 a$} & Right & $23.57 \pm 2.6$ & $18.3-30.98$ \\
\hline & Left & $23.04 \pm 2.6$ & $17.05-29.75$ \\
\hline \multirow[t]{2}{*}{$5 b$} & Right & $28.78 \pm 3.0$ & $28.78 \pm 3.0$ \\
\hline & Left & $28.32 \pm 2.6$ & $21.4-35.4$ \\
\hline \multirow[t]{2}{*}{$6 a$} & Right & $13.31 \pm 1.82$ & $7.43-17.48$ \\
\hline & Left & $14.01 \pm 2.06$ & $7.59-18.42$ \\
\hline \multirow[t]{2}{*}{$6 b$} & Right & $9.92 \pm 0.92$ & $8.48-11.56$ \\
\hline & Left & $9.69 \pm 0.54$ & $8.37-10.5$ \\
\hline
\end{tabular}

Table 4

Measurement values for parameters measured on CT scans

\begin{tabular}{llcc}
\hline Parameter & Side & Mean \pm SD (in mm) & Range ( in mm) \\
\hline \multirow{2}{*}{ CT1a } & Right & $21.96 \pm 1.2$ & $18.8-27.3$ \\
& Left & $22.84 \pm 1.92$ & $16.2-26.6$ \\
CT1b & Right & $13.2 \pm 1.68$ & $10.8-16.7$ \\
& Left & $13.38 \pm 1.71$ & $11.7-16.1$ \\
CT2a & & $33.4 \pm 2.91$ & $27.2-38.2$ \\
CT2b & & $28.12 \pm 1.74$ & $22.4-33.6$ \\
CT 4a & Right & $26.42 \pm 2.32$ & $21.2-32.6$ \\
& Left & $25.94 \pm 2.68$ & $19.2-32.4$ \\
CT 4b & Right & $15.2 \pm 1.38$ & $11.4-17.2$ \\
& Left & $14.9 \pm 1.52$ & $11.2-16.1$ \\
CT 5a & Right & $23.57 \pm 2.6$ & $23.04 \pm 2.6$ \\
& Left & $23.04 \pm 2.6$ & $17.05-29.75$ \\
CT 5b & Right & $28.2 \pm 2.6$ & $22.4-35.2$ \\
\hline
\end{tabular}




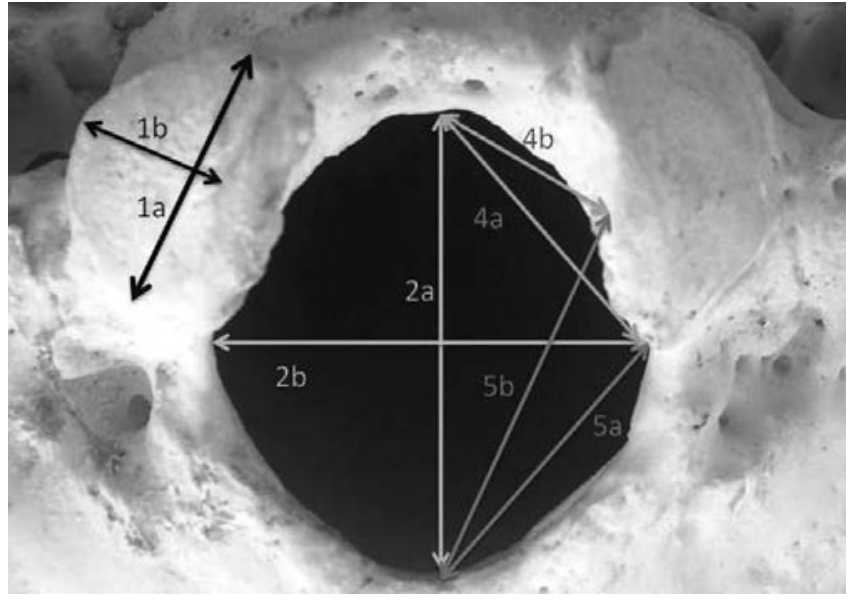

Figure 1. Parameters as measured on skulls and occipital bones. See also Table 1

\section{Discussion}

Knowledge of condylar anatomy helps the surgeon in making important decisions regarding the extent and direction of condylar drilling and minimizing injury and retraction of neural structures. The important preoperative information includes length, width, axis/directions and overriding of occipital condyle in the foramen magnum, the relationships of the condyles to the foramen magnum and the relationship of condyles to important structures such as hypoglossal canal. ${ }^{[10]}$

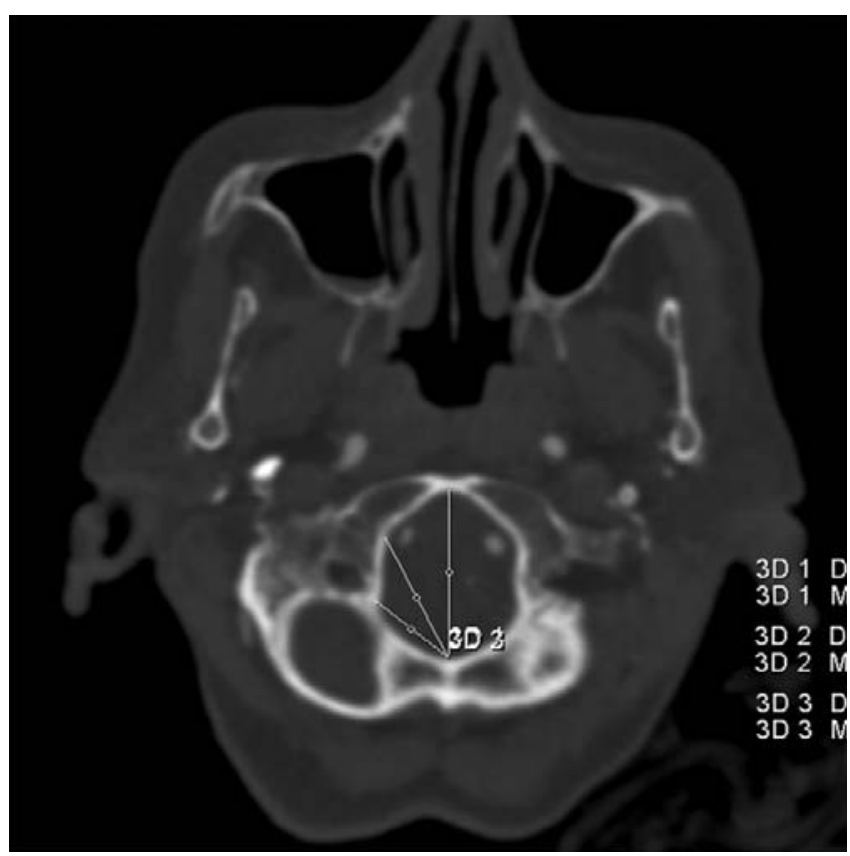

Figure 3. Anterior margin of foramen magnum to posterior end and midpoint of medial border of occipital condyles (CT $4 a$ \& CT 4b).

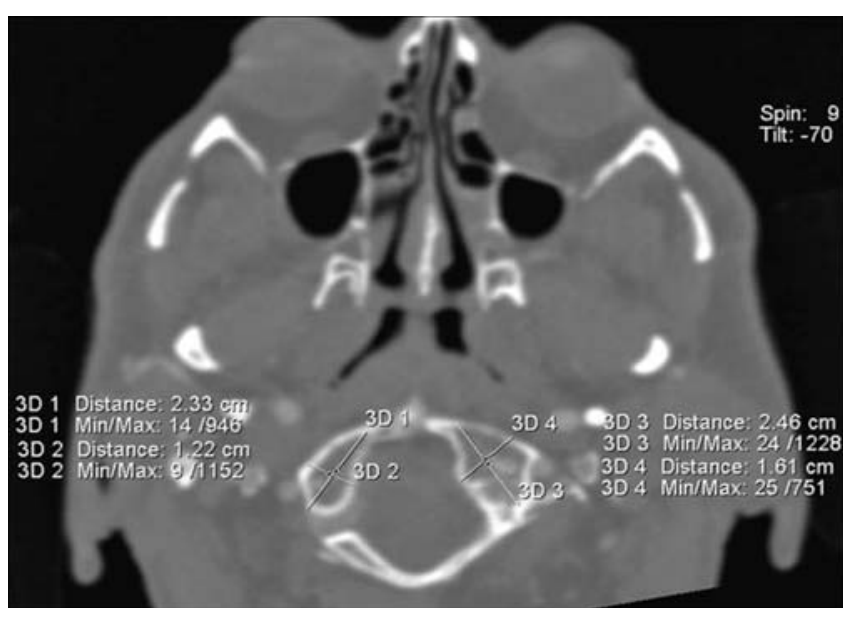

Figure 2. Length and width of occipital condyle (CT 1a \& CT 1b).

Condylar drilling is an important step in the transcondylar extension of the far lateral approach. ${ }^{[1]}$ The knowledge of length of the occipital condyle along its long axis and width of condyle helps the resection of the posterior $1 / 3 \mathrm{rd}$ of the occipital condyle safely. In this study, the long axis of occipital condyles ranged between 15.24-28.7 mm, which was consistent with the measurement taken on CT scans ie. 16.2-27.3 mm. The average length found by Wen et al. ${ }^{[6]}$ was $21 \mathrm{~mm}$ and the range was $18-24 \mathrm{~mm}$.

The removal of approximately the posterior $1 / 3 \mathrm{rd}$ of occipital condyle is required to reach the lateral aspect of the intracranial end of the hypoglossal canal. This is located about $5 \mathrm{~mm}$ below the jugular tubercle and $5 \mathrm{~mm}$ above the junction of posterior and middle third of the occipital condyle. ${ }^{[7]}$ The extracranial end of hypoglossal canal is located immediately above the junction of anterior and middle third of occipital condyle and medial to the jugular foramen. ${ }^{[5]}$ The posterior $2 / 3 \mathrm{rd}$ of the occipital condyle can be sacrificed as the direction of the canal is anterolateral, implying thereby that further drilling should be done anteriorly and laterally (Figure 6). The distances of inner and outer openings of hypoglossal canal from the midpoint of medial border of occipital condyle ought to be an important surgical guide in extension of condylar drilling. In our study, the distance of outer and inner foramen of hypoglossal canal from the midpoint of medial border was ranging between 7.43$18.42 \mathrm{~mm}$ and 8.37-11.56 mm. Wen et al. ${ }^{[6]}$ has mentioned about the distance from the posterior edge of occipital condyle to posterior edge of hypoglossal canal which was $8.4 \mathrm{~mm}$ and range between $6-10 \mathrm{~mm}$. 


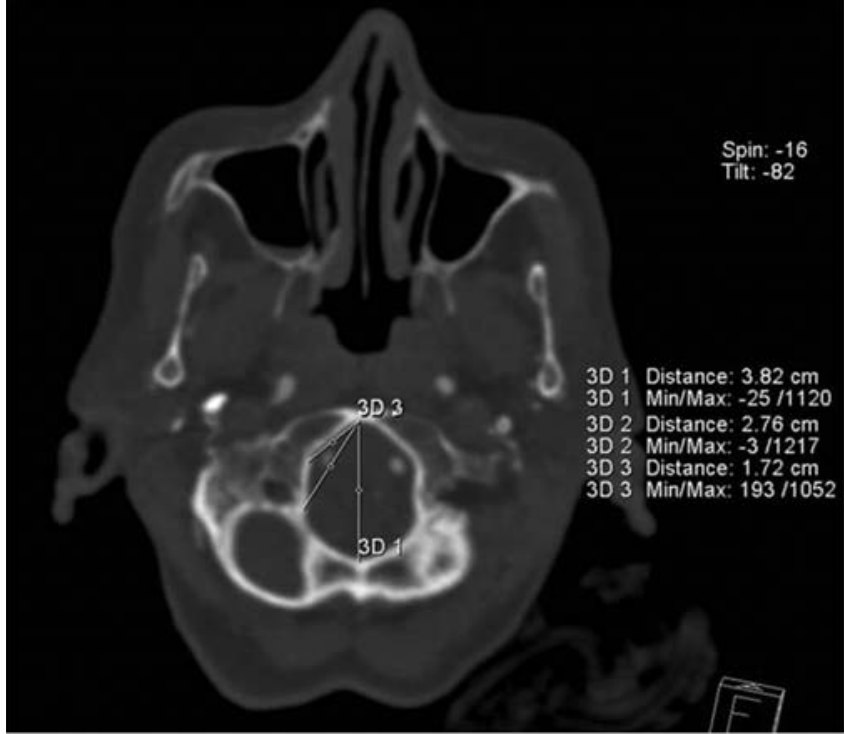

Figure 4. Anteroposterior and transverse diameters of foramen magnum (CT 2a \& CT 2b)

The anteroposterior and transverse diameters of foramen magnum and the amount of overriding of

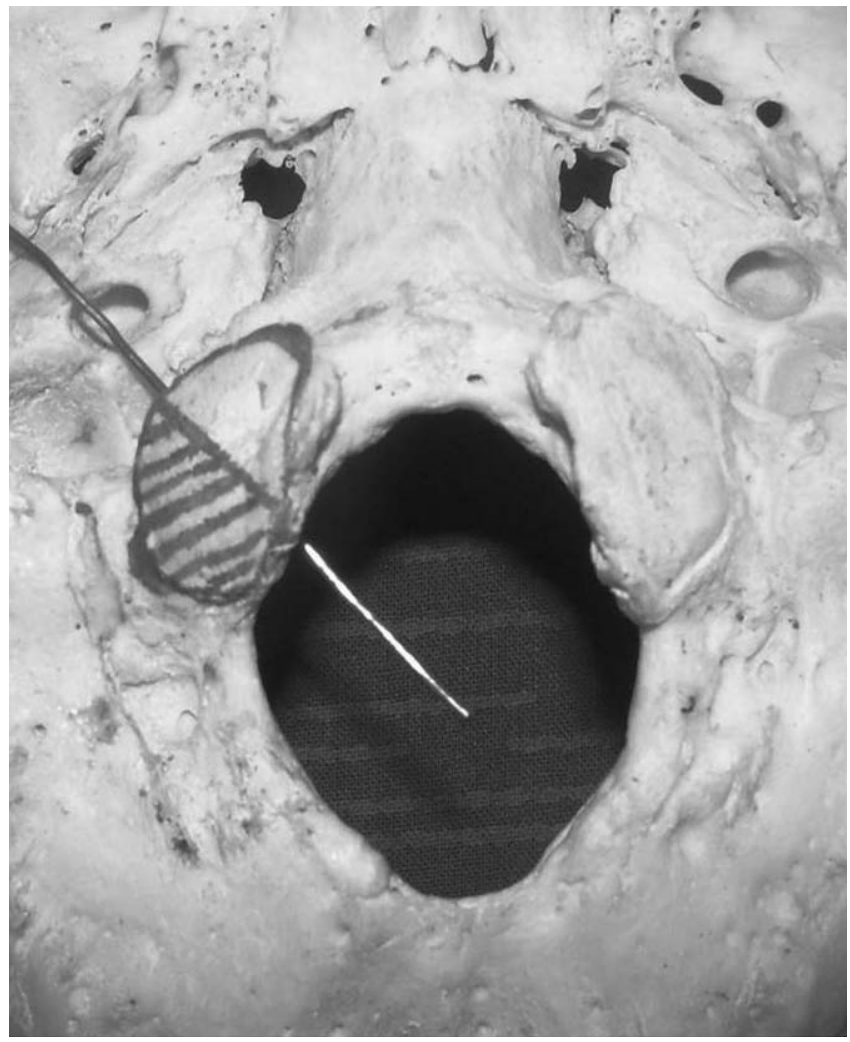

Figure 6. A probe passing through hypoglossal canal, showing direction of canal. Direction of probe shows medially posterior $1 / 3 \mathrm{rd}$ and laterally posterior 2/3rd of occipital condyle can be removed safely.

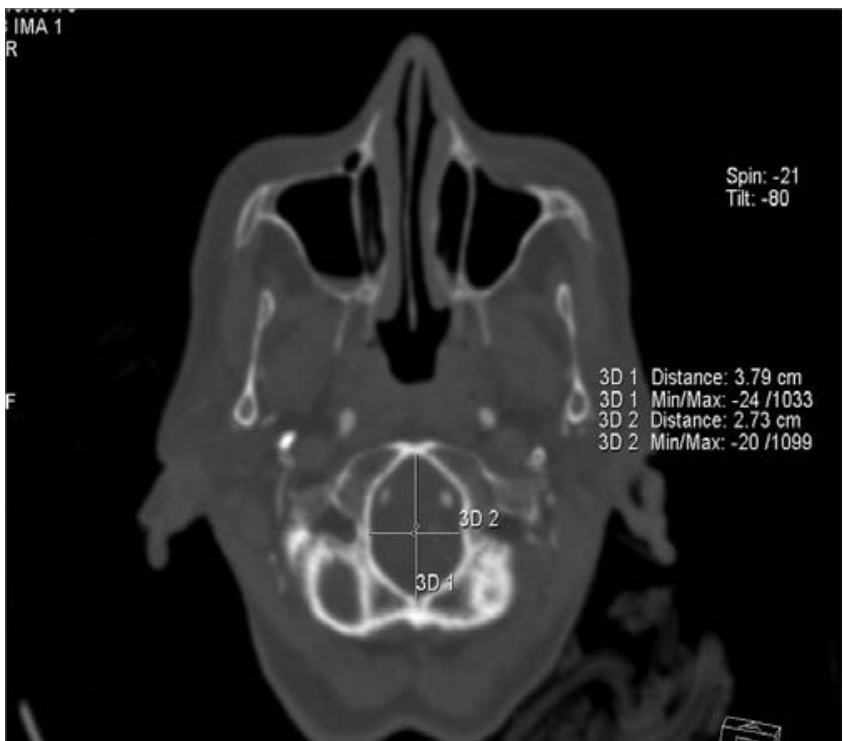

Figure 5. Posterior margin of foramen magnum to posterior ends and midpoint of medial border of occipital condyles (CT 5a \& CT 5b)

occipital condyle in the foramen magnum would help in calculating the area of surgical field. We have observed that the size, shape and overriding of occipital condyle in to the foramen magnum can alter the area of surgical field. The overriding of occipital condyle can range from 0-10.1 mm eg. A patient with small foramen magnum and relatively large occipital condyles would definitely require condylar drilling and transcondylar approach would be a safer approach.

The distances from the posterior midline of foramen magnum to the posterior border and midpoint of occipital condyle represent the width of surgical exposure in suboccipital craniotomy and 50\% condylar drilling respectively. The lateral exposure is increased in $50 \%$ drilling as compared to suboccipital craniotomy. Our study showed an average increase of exposure by $5 \mathrm{~mm}$ $(22 \%)$ for $50 \%$ condylar resection. Wanebo and Chicoine10 found an increase in exposure by $7 \mathrm{~mm}$ (30\%) for $50 \%$ transcondylar resection. The distances from the anterior midline of foramen magnum to the posterior border and midpoint of occipital condyle represent the angle of exposure in suboccipital craniotomy and $50 \%$ condylar drilling respectively. Wanebo and Chicoine10 found values of $54.3 \pm 5.7^{\circ}$ for $50 \%$ transcondylar resection.

The recognition and understanding of the correlations among these important structures and an understanding of the possible variations helps to distinguish the normal from the potentially abnormal and consequently avoid misinterpretations during surgery. ${ }^{[12]}$ 


\section{Conclusion}

The far lateral transcondylar approach provides better exposure of the ventrolateral foramen magnum and inferior clivus. The removal of lesions from this site is made easier through a shortened and widened angle of exposure. Morphometric parameters measured can be used for the estimation of extent of condylar removal and to perform transcondylar approach without harming functional structures. These parameters can be assessed preoperatively by CT imaging.

\section{References}

1. Bertalanffy $H$, Seeger $W$. The dorsolateral, suboccipital transcondylar approach to the lower clivus and anterior portion of the craniocervical junction. Neurosurgery 1991;29:815-21.

2. Banerji D, Behari S, Jain VK. Extreme lateral transcondylar approach to the skull base. Neurol India 1999;47:22-30.

3. Babu RP, Sekhar LN, Wright DC. Extreme lateral transcondylar approach: technical improvements and lessons learned. J Neurosurg 1994;81:49-59.

4. al-Mefty O, Borba LA, Aoki N, Angtuaco E, Pait TG. The transcondylar approach to extradural nonneoplastic lesions of the craniovertebral junction. J Neurosurg 1996;84:1-6.
5. Menezes AH. Surgical approaches: postoperative care and complications "posterolateral-far lateral transcondylar approach to the ventral foramen magnum and upper cervical spinal canal". Childs Nerv Syst 2008;24:1203-7.

6. Wen HT Rhoton AL Jr, Katsuta T, de Oliviera E. Microsurgical anatomy of the transcondylar, supracondylar and paracondylar extensions of the far-lateral approach. J Neurosurg 1997;87:55585.

7. Rhoton AL. The far lateral approach and its transcondylar, supracondylar and paracondylar extensions. Neurosurg 2000;47(3 Suppl):S195-209.

8. Gruber P, Henneberg M, Böni T, Rühli FJ. Variability of human foramen magnum size. Anat Rec (Hoboken) 2009;292:1713-9.

9. Tubbs RS, Griessenauer CJ, Loukas M, Shoja MM, Cohen-Gadol AA. Morphometric analysis of foramen magnum. An anatomical study. Neurosurg 2010;66:385-8.

10. Wanebo JE, Chicoine MR. Quantitative analysis of the transcondylar approach to the foramen magnum. Neurosurgery 2001;49:934-43.

11. Xiong J, Chen G, Ji R, et al. Morphometric analysis and microsurgical anatomy for far lateral transcondylar approach. Journal of US-China Medical Science 2008;5:27-36

12. Keskil S, Gözil R, Çalgüner E. Common surgical pitfalls in the skull. Surg Neurol 2003;59:228-31.

Correspondence to: Dr. Gaurav Agnihotri

C/o Satish Mahajan, House No 44 AB, Lane No.2,

Gopal Nagar, Majitha Road, Amritsar, Punjab, India

Phone: +919815542792

e-mail: anatomygaurav@rediffmail.com

Conflict of interest statement: No conflicts declared. 